\title{
Organizational Support-Citizenship Behavior Relationship in Malaysian Higher Educational Institutions
}

\author{
Mohamed Idrus Rosafizah', Mansor Azlin Norhaini ${ }^{1}{ }^{*}$, Idris Khairuddin ${ }^{2}$ \\ ${ }^{1}$ Faculty of Education, Universiti Kebangsaan Malaysia, Selangor, Malaysia \\ ${ }^{2}$ Faculty of Educational Studies, Universiti Pertanian Malaysia, Selangor, Malaysia \\ Email: *azlinmansor@ukm.edu.my
}

How to cite this paper: Rosafizah, M. I., Norhaini, M. A., \& Khairuddin, I. (2020). Organizational Support-Citizenship Behavior Relationship in Malaysian Higher Educational Institutions. Creative Education, 11, 2293-2304.

https://doi.org/10.4236/ce.2020.1111168

Received: October 7, 2020

Accepted: November 15, 2020

Published: November 18, 2020

Copyright $\odot 2020$ by author(s) and Scientific Research Publishing Inc. This work is licensed under the Creative Commons Attribution International License (CC BY 4.0).

http://creativecommons.org/licenses/by/4.0/

\begin{abstract}
Organizational citizenship behavior (OCB) is a unique aspect of employees' behaviors in the workplace and is a prerequisite for organizational effectiveness and efficacy. It is essential in every organization, including in higher education settings. Previous studies have shown that organizational support is a possible stimulating condition for OCB; however, few studies have been carried out in a higher education context, especially in Malaysia. This study therefore empirically examines the underlying mechanism of the organizational support-OCB relationship in Higher Educational Institutions in Malaysia. Data were gathered through questionnaires administered to 487 staff at five universities in Malaysia. Structural equation modeling using AMOS was employed to analyze the data. The results showed organizational support positively and significantly contributed to citizenship behavior at both an individual level and an organizational level. The implications of the findings are discussed and suggestions made for future research on the organizational support-OCB relationship in the context of Malaysian Higher Educational Institutions.
\end{abstract}

\section{Keywords}

Higher Educational Institution, Organizational Citizenship Behavior, Organizational Support, Social Exchange Theory

\section{Introduction}

In the contemporary world of the twenty-first century, Higher Education Institutions (HEIs) are continually being challenged by new opportunities, new situations, new markets, and new technologies (Azman et al., 2010; Beerkens, 2010; 
Pucciarelli \& Kaplan, 2016; Selvaratnam, 2016). One of the most important factors in ensuring the effectiveness and success of HEIs is a culture of practicing positive organizational behavior from top management down to the bottom level of the institution. This encourages leaders to focus on peoples' strengths and ameliorate their weaknesses (Seligman \& Csikszentmihalyi, 2000).

The main components in ensuring the elevation of effectiveness of HEIs are the staff. The staff exhibit various behaviors in an organization. This ranges from minimal behaviors that are performed reluctantly as a means to maintain membership to behaviors that go beyond expectations to benefit others as well as the organization. The commitment and willingness of staff to voluntarily go beyond their job descriptions and responsibilities when completing their assigned tasks are termed organizational citizenship behavior (OCB). This is rapidly becoming a unique aspect of staff behaviors in the workplace. A key aspect of OCB is that voluntary behavior which benefits others is not part of the employee's job description but will benefit the organization in the long run (Abdulrab et al., 2018; Chiaburu et al., 2015; Gupta et al., 2016; Indrawiani et al., 2018, Zhang et al., 2017).

Previous studies have shown that organizational support is a possible stimulating condition that serves to cultivate desirable behavior such as OCB (Abdulrab et al., 2018; Chiaburu et al., 2015; Gupta et al., 2016; Indrawiani et al., 2018). These researchers have found that staff who perceive high levels of support from their organization will feel obligated toward the organization and will respond in kind through voluntary behavior that goes beyond their job expectation (Abdulrab et al., 2018; Chiaburu et al., 2015; Gupta et al., 2016; Indrawiani et al., 2018). However, less scholarly attention has been paid to the fundamental reasons as to why perceptions of organizational support may prompt staff to reciprocate in this way. Furthermore, previous studies have examined this relationship by focusing on only one dimension of OCB and have done so primarily in a western context.

This study therefore addresses these gaps by examining the underlying mechanism of organizational support in relation to two dimensions of OCB (citizenship behavior toward individuals and citizenship behavior toward organizations) among staff in Malaysian HEIs. It first conducts a thorough review of existing literature in order to understand how this relationship can direct Malaysian HEIs to stimulate and sustain the strengths and psychological capacities of staff to attain a competitive advantage that will benefit Malaysian Higher Educational Institutions in the long term.

\section{Literature Review}

1) Organizational support

Eisenberger et al. (2001) defined perceived organizational support as staff members' awareness of the extent to which the organizations value their contribution and care about their well-being. Eisenberger et al. (2001) further argued that the readiness of the organization to reward the efforts of its staff while si- 
multaneously meeting their socio-emotional needs will cultivate their beliefs regarding the extent to which the organization values their efforts and prioritizes their well-being. The causal effect of staff perceptions of organizational support on their attitudes and behaviors at work can be explained through a combination of social exchange theory and the norm of reciprocity.

Social exchange theory describes the process of exchanges made between two parties in accordance with the principle of mutual benefit. According to Lester et al. (2008), this principle posits that an individual who is the recipient of a benefit from another party should also offer a benefit. Thus, when employees perceive that they are involved in a long-term exchange relationship with an organization, they are more willing to engage in OCB to promote its interests (Eisenberger et al., 2001; Lester et al., 2008). This focus on the importance of mutual benefit in social relationships aligns with the norm of reciprocity. In this respect, employees' positive perceptions that the organization genuinely values their contributions and cares about their well-being provides them with reasons to reciprocate by willingly contributing to the organization (Eisenberger et al., 2001). Therefore, the present study assumes that organizational support is a variable that potentially influences OCB through social exchange theory and the norm of reciprocity.

2) Organizational Citizenship Behavior (OCB)

The concept of OCB was first introduced by Barnard in 1938 who defined it as a cooperative behavior that emphasizes the importance of spontaneous contributions by individuals that go beyond the content of contractual obligations to achieve organizational goals. This concept was then extended in 1964 by Katz who found that spontaneous behaviors beyond traditional job requirements play an important role in organizational effectiveness. Katz identified two basic types of behaviors in an organization: in-role behavior and extra-role behavior. He explained that in-role behaviors were expected for the accomplishment of job duties while extra-role behaviors refer to a series of actions that are not included in the assigned job description of an employee (Katz, 1964). These extra-role behaviors go beyond prescribed job requirements to increase production and contribute to organizational effectiveness (Katz \& Kahn, 1966). They would later be conceptualized and validated in empirical studies as OCB.

An extensive study of OCB has been ongoing for the past two decades in behavioral science, which has focused its research on positive oriented human resources. OCB is also known as "the good soldier syndrome", Contextual Performance, Organizational Spontaneity, Civic Organizational Behavior, and Prosocial Organizational Behavior (Borman \& Motowidlo, 1997; Brief \& Motowidlo, 1986; George \& Brief, 1992; George \& Jones, 1997; Kabasakal et al., 2011; Organ et al., 2006; Podsakoff et al., 2000). All these terms are used synonymously with OCB as they all emphasize facets of behavior that encompass cooperation with and facilitating other employees in the workplace. Sometimes they refer to the mere display of behavior by an employee who goes an extra mile to voluntarily undertake tasks that go beyond formal job descriptions and role expectations 
(Kabasakal et al., 2011; Podsakoff et al., 2000).

Indeed, most researchers refer to $\mathrm{OCB}$ as organizationally beneficial behaviors and gestures voluntarily conducted by the employee that are not required in the job description and contribute to organizational effectiveness in numerous ways. For instance, OCB: 1) improves employee and managerial output (Awang \& Ahmad, 2015; Organ, 1997, Podsakoff et al., 2000); 2) assists in coordinating activities within and across work groups (Gupta et al. 2017; Deng \& Guan 2017; Mahembe \& Engelbrecht, 2014); 3) maximizes the organization's ability to attract and retain talent (Kabasakal et al., 2011; Podsakoff et al., 2000; Vivek, $2016)$; 4) enhances the stability of organizational performance (Gupta et al., 2017); and 5) enables organizations to cope and compete in an aggressive environment (Podsakoff et al., 2000). The countless benefits of OCB to organizational productivity, performance, effectiveness, and efficiency render it a potentially vital behavior in the context of Malaysian HEIs.

3) Organizational support-OCB relationship in Malaysian higher education

Higher educational institutions (HEIs) are defined as organizations that provide education beyond secondary level to increase the value of individuals for the betterment of society (Sunder, 2016). Tertiary education institutions play an extremely important role in ensuring strong social mobility and economic growth for Malaysia while HEIs serve as an important platform upon which to connect the knowledge, skills, and expertise required for the new global economy (Azman et al., 2010; Selvaratnam, 2016). In the globalized world of the twenty-first century, HEIs are being tested by new opportunities, new situations, new markets, and new technologies (Azman et al., 2010; Beerkens, 2010; Pucciarelli\& Kaplan, 2016; Selvaratnam, 2016). Thus, the role of the higher education system is transforming into that of a provider of high-level knowledge and skills. This will ensure an educated workforce is available that can meet the needs of a competitive global market (Selvaratnam, 2016).

Indrawiani et al. (2018) conducted research on the contributions of organizational support and OCB among 136 employees in Indonesia. They found that high levels of organizational support created a feeling of obligation among employees to reciprocate their employers' commitment by engaging in behaviors that support organizational goals. Furthermore, when employees perceived high levels of support from their organization, they felt obligated to respond in kind towards the organization by making a voluntary effort to go beyond the stipulated requirements of their jobs (Indrawiani et al., 2018).

Similarly, Chiaburu et al. (2015), Gupta et al. (2016), Nisar et al. (2014), and Paramaartha et al. (2019) studied the role of organizational support in nurturing citizenship behavior. They found that high levels of perceived organizational support whereby employees believe that the organization cares and values their service leads to positive attitudes and behavioral outcomes such as higher engagement, commitment, increased work satisfaction, and OCB. Moreover, they found that employees with high levels of perceived organizational support exhibited more trust, commitment, and job involvement as a result of incorporating 
organizational membership into their identities

\section{Purpose of Research}

Empirical research has therefore shown that organizational support and OCB influence the behaviors exhibited by staff. However, not enough attention has been paid thus far to this relationship in the field of higher education in Malaysia. Moreover, previous researchers have focused only on one-dimensional OCB studies. It is therefore important to explore a two-factor model in terms of the intended target or beneficiary of the citizenship behavior, whether this is more toward the individual (OCBI) or the organization (OCBO). Given the issues discussed, it was therefore hypothesized that:

$\mathrm{H}_{1}$-There is a positive and significant relationship between organizational support and OCBI in Malaysia HEIs.

$\mathrm{H}_{2}$-There is a positive and significant relationship between organizational support and OCBO in Malaysia HEIs.

\section{Methodology}

\section{Research Design}

This correlational study aimed to determine the importance of organizational support in cultivating positive behavior through OCB. A quantitative technique was employed to analyze the relationship among variables. Data were collected from a cross sectional self-administered survey. The sample comprised 487 members of staff from five universities in Malaysia by using the formula for the minimum sample size based on Cochran (1977) sampling formula. This research used multistage sampling techniques to divide large populations of RUs support staff into stages to make the sampling process more practical. A combination of proportionate stratified sampling and simple random sampling techniques was used whereby the staff were stratified into three groups based on their grade that consist of Group 1: Grade 1 to 16; Group 2: Grade 17 to 26 and Group 3: Grade 27 to 40 . These subsets of the strata were then pooled to form a simple random sample using a random number generator to create a list of random numbers which will appear in Random Number Table so that each person remaining in the population has the same probability of being selected for the sample. Structural Equation Modeling (SEM) with Analysis of Moment Structures (AMOS) was utilized to analyze the data using the IBM SPSS version 25 statistical package.

\section{Measures}

Organizational support was measured by a short version of the Survey of Perceived Organizational Support Survey (SPOS) developed by Eisenberger et al. (1997) which consists of 8 items. All items were measured on a 7-point scale ranging from 1 = strongly disagree to $7=$ strongly agree. The reliability alpha has been reported to range from .81 to .92 (Chiaburu et al., 2015; Eisenberger et al., 2002; Zhang et al., 2017) which suggests excellent internal consistency. In this study, it was found to be 95 . OCB was measured using 20 items based on Fox et 
al. (2012), where the first ten items were employed to measure OCBI and the next ten items were utilized to measure OCBO. This scale was reported as having high reliability ranging from .79 to .91 for OCBI and .87 to .94 for ОСВO. The reliability coefficient of the scale for the present study was found to be .92 for both OCBI and OCBO.

\section{Data Analysis}

\section{Demographic Profile}

Of the 487 respondents who participated in the study, 314 (64.5\%) were female and 173 (35.5\%) were male. Their ages ranged from 19 to 60 years old, with $23.8 \%$, aged 30 years and below, $45.6 \%$ aged 31 to 40 years old, $16.4 \%$ aged 41 46 years old, and $14.2 \%$ aged 50 years and above. Respondents working experience varied from 2 to more than 30 years. In terms of academic qualifications, $2.1 \%$ (10 respondents) had at least a primary school degree (SRP/PMR/LCE), 45\% (219 respondents) had an upper school degree (SPM/SPMV/GCE), 42.9\% (209 respondents) had a Diploma/STPM/HSC, and 10.1\% (49 respondents) had a Bachelor's degree.

\section{Assumption Test}

The skewness of the variables ranged between -.077 to -.911 while kurtosis ranged between -.828 to .783 . All these values were within the acceptable threshold of \pm 2 for skewness and \pm 7 for kurtosis, as suggested by Bryne (2010). This indicates that all the variables were normally distributed. The variables were also linearly related as the dots in the scatterplot were oval-shaped rather than square. The Normal P-P plot of Regression Standardized Residual showed that the relationship between the dependent variable and independent variable was linear and positive. The straight line on the scatter plot thus suggested there was no violation of the linearity assumption. The scatterplot of residuals versus predicted values exhibited the same scatter and showed the points were approximately the same distance from the line; the assumption of homoscedasticity was therefore met as the residuals were equal across the regression line. Moreover, the results also showed that the VIF values for all variables were 1.00, which was less than 10 and therefore there were no multicollinearity issues.

\section{Tests for Validity and Reliability}

Convergent validity refers to a set of variables or items that are assumed to measure a construct and share a high proportion of common variance (Hair et al., 2013). This was tested using factor loading in which the loading of constructs was as follows: OCBI (.604 to .768), ОСВО (.614 to .887), and organizational support (.710 to .920). The Average Variance Extracted (AVE) for the three constructs was as follows: OCBI (.529), OCBO (.537) and organizational support (.723). Finally, the reliability coefficients for the three constructs were as follows: OCBI (.918), OCBO (.920), and organizational support (.954). This indicates that the measures had good internal consistency and represent the same construct. Thus, the measurement instrument was valid and enabled the results to be accurately interpreted (Table 1). 
Table 1. Construct reliability, average variance extracted, and squared correlation coefficient.

\begin{tabular}{ccccc}
\hline \multirow{2}{*}{ Variable } & CR & \multicolumn{3}{c}{ AVE and $r^{2}$} \\
\cline { 3 - 5 } & & OCBI & OCBO & Organizational Support \\
\hline OCBI & .918 & .529 & & \\
OCBO & .920 & .272 & .537 & .723 \\
Organizational Support & .954 & .415 & .141 & .00 \\
\hline
\end{tabular}

Note: $\mathrm{CR}=$ Construct Reliability, AVE = Average Variance Extracted (on the diagonal), $\mathrm{r}^{2}=$ coefficient determination (on the off-diagonal).

\section{Measurement Model}

The plausibility of the proposed model was also tested through model fit statistics using AMOS. The measurement model consisted of three latent constructs: organizational support, OCBI, and OCBO. The assessment of standardized factor loading, which consisted of 28 items obtained from the individual CFAs, indicated that all items had positive values that ranged between .604 to .920 . Thus, all were greater than .50. The values for fit indices were as follows: Relative Chi-Square $=2.95, \mathrm{RMSEA}=.06, \mathrm{CFI}=.93, \mathrm{IFI}=.93, \mathrm{NFI}=.90$ and TLI $=.93$. These all met the requirement recommended by Hair et al. (2013), who suggested that if three to four of the Goodness-of-Fit indices met the requirement, then the model was an acceptable fit. Therefore, the measurement model was a good fit based on the factor loading of the revised individual CFAs and fit indices. A summary of the model fit for the measurement model is presented in Table 2.

Discriminant validity was tested by comparing the AVE for two constructs against the square of the correction estimation $\left(\mathrm{r}^{2}\right)$. The AVEs of variables ranged from .50 to .55 , which exceeded the 0.5 cut-off point. Furthermore, comparing the squared-correlation $\left(\mathrm{r}^{2}\right)$ values with the AVE showed that the $\mathrm{r}^{2}$ values were less than the AVEs. This indicated that each construct was distinct. In addition, the correlation between variables ranged from .37 to .74 which was less than .90, indicating there were no multicollinearity issues and the constructs could be discriminated. In short, the constructs met the standards for discriminant validity. Table 3 presents the detailed results of the inter-correlation of the measurement model.

\section{Structural Model}

The focus of the structural model was to examine and test the hypothesized relationships between exogenous and endogenous variables. Testing of the structural model showed that the values for fit indices met the recommended acceptable values. These values were as follows: Relative Chi-Square $=3.12$, $\mathrm{RMSEA}=.07, \mathrm{CFI}=.93, \mathrm{IFI}=.93$, and TLI $=.92$. Therefore, the structural model was a good fit. A summary of the model fit for the structural model is presented in Table 4 . This model was then used to analyze the 4 hypothesized relationships among the latent variables. 
Table 2. Model fit for the measurement model.

\begin{tabular}{ccccccc}
\hline Fit Indices & $\begin{array}{c}\text { Relative Chi } \\
\text { Square }(>5.0)\end{array}$ & $\begin{array}{c}\text { RMSEA } \\
(\leq .08)\end{array}$ & $\begin{array}{c}\text { CFI } \\
(\geq .90)\end{array}$ & $\begin{array}{c}\text { IFI } \\
(\geq .90)\end{array}$ & $\begin{array}{c}\text { NFI } \\
(\geq .90)\end{array}$ & $\begin{array}{c}\text { TLI } \\
(\geq .90)\end{array}$ \\
\hline Measurement Model & 2.949 & .063 & .931 & .931 & .900 & .925 \\
\hline
\end{tabular}

Table 3. Inter-correlation of the measurement model.

\begin{tabular}{|c|c|c|c|c|c|}
\hline \multirow{2}{*}{ Construct } & \multirow{2}{*}{$\begin{array}{c}\text { Factor } \\
\text { Correlation }\end{array}$} & \multirow{2}{*}{$\begin{array}{l}\text { Correlation } \\
\text { Squared }\end{array}$} & $\mathrm{AVE}_{1}$ & $\mathrm{AVE}_{2}$ & \multirow{2}{*}{$\begin{array}{c}\text { Discriminant } \\
\text { Validity }\end{array}$} \\
\hline & & & \multicolumn{2}{|c|}{ (AVEs should be $>r^{2}$ ) } & \\
\hline OCBI $\ominus \mathrm{CBO}$ & .522 & .272 & .529 & .537 & Valid \\
\hline OCBI $\Theta S$ & .644 & .415 & .529 & .723 & Valid \\
\hline $\mathrm{OCBO} \Theta \mathrm{S}$ & .375 & .141 & .537 & .723 & Valid \\
\hline
\end{tabular}

Table 4. Summary of model fit for the structural model.

\begin{tabular}{ccccccc}
\hline Fit Indices & $\begin{array}{c}\text { Relative Chi } \\
\text { Square }(>\mathbf{5 . 0})\end{array}$ & $\begin{array}{c}\text { RMSEA } \\
(\leq .08)\end{array}$ & $\begin{array}{c}\text { CFI } \\
(\geq .90)\end{array}$ & $\begin{array}{c}\text { IFI } \\
(\geq .90)\end{array}$ & $\begin{array}{c}\text { NFI } \\
(\geq .90)\end{array}$ & $\begin{array}{c}\text { TLI } \\
(\geq .90)\end{array}$ \\
\hline Structural Model & 3.123 & .066 & .925 & .925 & .893 & .918 \\
\hline
\end{tabular}

\section{Hypothesized Relationships}

The objective in this study was to examine the influence of organizational support on OCBI and OСBO. Two hypotheses were tested. The result showed that organizational support was positively and significantly related to OCBI ( $\beta$ $=.648, \mathrm{p}<.05)$. Organizational support explained $42 \%$ of the variance, signifying a moderate relationship with OCBI. The results also revealed that organizational support was positively and significantly related to OCBO $(\beta=.385, \mathrm{p}<.05)$. Organizational support explained $14.8 \%$ of the variance, signifying a low relationship with OCBO (Table 5).

\section{Discussion}

This study aimed to predict the relationship between organizational support and two dimensions of OCB (i.e., OCBI and OCBO). The results showed that organizational support positively and significantly contributed to both OCBI and OCBO. This finding was consistent with Gupta et al.'s (2016) research on the relationship between psychological contract breaches, organizational support, work engagement, and OCB among 750 nurses in India. They found that organizational support exerts its influences on work-related outcomes such as OCB. They also established that high levels of perceived organizational support, whereby employees' believe that the organization cares and values their service, leads to employees engaging in positive voluntary work that benefits the organization in the long term.

The present results revealed that high levels of perceived organizational support were closely identified with the HEIs. This was consistent with Kurtessis et al.'s (2017) meta-analytic evaluation of perceived organizational support based 
Table 5. Results of Hypotheses Testing $\left(\mathrm{H}_{1}\right.$ to $\left.\mathrm{H}_{2}\right)$.

\begin{tabular}{ccccccccc}
\hline \multicolumn{2}{c}{ Hypotheses } & & Causal Path & b & SE & Beta & C.R & p \\
\hline $\mathrm{H}_{1}$ & OS & $\rightarrow$ & OCBI & .448 & .041 & .648 & 11.063 & .000 \\
$\mathrm{H}_{2}$ & OS & $\rightarrow$ & OCBO & .299 & .037 & .385 & 8.049 & .000 \\
\hline
\end{tabular}

on results from 558 studies. Kurtessis et al. found that employees with a high level of perceived organizational support exhibited greater levels of trust, commitment, and job involvement. Other researchers have also studied the relationship between organizational support and OCB and have found that organizational support has a positive and strong influence on OCB (Chiaburu et al., 2015; Gupta et al., 2016; Indrawiani et al., 2018; Nisar et al. 2014; Paramaartha et al., 2019). All concluded that organizational support was the basis for OCB in that employees were likely to act as good citizens by reciprocating the support provided by their organization.

In the context of Malaysian HEIs, favorable treatment between HEI management and staff was reciprocated when mutual benefits were received by staff as this impelled them to willingly engage in an exchange by voluntarily going beyond the call of duty. This reciprocity can be seen as an application of social exchange theory, where staff feel obligated to behave in ways that maintain the balance of the exchange relationship. This norm of reciprocity suggested that, when staff perceived their HEIs as supportive and caring about their well-being, they felt obligated to respond with favorable behavior such as OCB and were more inclined to commit to their university.

Based on the above discussion, it can therefore be concluded that organizational support is an important construct that contributes to OCB. This present study provided empirical evidence to show that organizational support positively and significantly contributes to citizenship behavior at both an individual level and an organizational level. The role of organizational support is important in nurturing citizenship behavior as it made the staff feel secure and safe and led them to voluntarily to carry out their tasks beyond their official job descriptions, which will benefit Malaysian HEIs in the long term.

\section{Implication and Suggestion}

This study verified previous findings which showed that organizational support is beneficial in cultivating positive voluntary behavior in Malaysian HEIs. It added to the OCB literature by examining the significant contribution of organizational support-OCB relationship in the context of Malaysian HEIs. It contributes to the overall body of knowledge by examining the relationship between organizational support and different types of citizenship-like behaviors (i.e., OCBI and OCBO) at an individual-level or organizational-level in a developing country (i.e., Malaysia).

Social exchange theory was employed as the underlying theory to understand the norm of reciprocity whereby mutual benefits received by staff impelled them 
to voluntarily go beyond the call of duty. Future research could therefore utilize social cognitive theory to explore how staff's cognitions may influence their voluntary behaviors. This theory implies that behavior is influenced by a combination of personal and environmental factors that interact and affect each other bi-directionally. Future research could therefore explore the relationship between both personal factors (resilience and self-efficacy) and work-related factors (organizational support) in cultivating employees' strengths through OCB (behavior). This will elucidate the fundamental association between behaviors, cognitions, personal factors, and the environment. It will show the bi-directional effects between these variables and how individuals acquire and maintain certain behavior patterns through these interactions. This will further add to the body of knowledge on OCB and social cognitive theory.

\section{Conclusion}

This current study has confirmed the importance of having a high level of organizational support, OCBI, and OCBO among staff in Malaysian HEI in the globalized world of the twenty-first century. This citizenship behavior impels staff to make an extra effort by undertaking tasks beyond their job description that will benefit the HEI in the long term. Establishing the importance of the organizational-OCB relationship in Malaysia HEIs will impel top management in HEIs to design suitable interventions that foster OCB by combining specific measures at both an organizational and an individual level. This study also confirmed the important role of HEIs in intensifying human resource strengths through OCB, which will contribute to their efficient and effective functioning in the globalized world of the twenty-first century.

\section{Funding}

This work was supported by Universiti Kebangsaan Malaysia Research Grant (GG2020-001 and GG2020-018).

\section{Conflicts of Interest}

The authors declare no conflicts of interest regarding the publication of this paper.

\section{References}

Abdulrab, M., Zumrah, A. R., Almaamari, Q., Al-Tahitah, A. N., Isaac, O., \& Ameenf, A. (2018). The Role of Psychological Empowerment as a Mediating Variable between Perceived Organizational Support and Organizational Citizenship Behaviour in Malaysian Higher Education Institutions. International Journal of Management and Human Science, 3, 1-14.

Awang, R., \& Ahmad, W. M. R. W. (2015). The Impact of Organizational Justice on Organizational Citizenship Behavior in Malaysian Higher Education. Mediterranean Journal of Social Sciences, 6, 674. https://doi.org/10.5901/mjss.2015.v6n5s2p674

Azman, N., Sirat, M., \& Karim, M. A. (2010). Building Future Scenarios for Malaysian 
Universities. Journal of Asian Public Policy, 3, 86-99. https://doi.org/10.1080/17516231003634112

Barnard, C. I. (1938). The Functions of the Executive (pp. 40-61). Cambridge, MA: Harvard University Press.

Beerkens, E. (2010). Global Models for the National Research University: Adoption and Adaptation in Indonesia and Malaysia. Globalisation, Societies and Education, 8, 369-391. https://doi.org/10.1080/14767724.2010.505099

Borman, W. C., \& Motowidlo, S. J. (1997). Task Performance and Contextual Performance: The Meaning for Personnel Selection Research. Human Performance, 10, 99-109. https://doi.org/10.1207/s15327043hup1002 3

Brief, A. P., \& Motowidlo, S. J. (1986). Prosocial Organizational Behaviors. Academy of Management Review, 11, 710-725. https://doi.org/10.5465/amr.1986.4283909

Chiaburu, D. S., Chakrabarty, S., Wang, J., \& Li, N. (2015). Organizational Support and Citizenship Behaviors: A Comparative Cross-Cultural Meta-Analysis. Management International Review, 55, 707-736. https://doi.org/10.1007/s11575-015-0253-8

Deng, X., \& Guan, Z. (2017). Creative Leaders Create "Unsung Heroes": Leader Creativity and Subordinate Organizational Citizenship Behavior. Frontiers of Business Research in China, 11, Article No.: 15. https://doi.org/10.1186/s11782-017-0013-7

Eisenberger, R., Armelli. S., Rexwinkel, B., Lynch, P. D., \& Rhoades, L. (2001). Reciprocation of Perceived Organizational Support. Journal of Applied Psychology, 86, 42-51. https://doi.org/10.1037/0021-9010.86.1.42

Eisenberger, R., Stinglhamber, F., Vandenberghe. C., Sucharski, I., \& Rhoades, L. (2002). Perceived Supervisor Support: Contributions to Perceived Organizational Support and Employee Retentions. Journal of Applied Psychology, 87, 565-573. https://doi.org/10.1037/0021-9010.87.3.565

Fox, S., Spector, P. E., Goh, A., Bruursema, K., \& Kessler, S. R. (2012). The Deviant Citizen: Measuring Potential Positive Relations between Counterproductive Work Behaviour and Organizational Citizenship Behaviour. Journal of Occupational and Organizational Psychology, 85, 199-220. https://doi.org/10.1111/j.2044-8325.2011.02032.x

George, J. M., \& Brief, A. P. (1992). Feeling Good-Doing Good: A Conceptual Analysis of the Mood at Work-Organizational Spontaneity Relationship. Psychological Bulletin, 112, 310-329. https://doi.org/10.1037/0033-2909.112.2.310

George, J. M., \& Jones, G. R. (1997). Organizational Spontaneity in Context. Human Performance, 10, 153-170. https://doi.org/10.1207/s15327043hup1002 6

Gupta, M., Shaheen, M., \& Reddy, P. K. (2017). Impact of Psychological Capital on Organizational Citizenship Behavior: Mediation by Work Engagement. Journal of Management Development, 36, 973-983. https://doi.org/10.1108/JMD-06-2016-0084

Gupta, V., Agarwal, U. A., \& Khatri, N. (2016). The Relationships between Perceived Organizational Support, Affective Commitment, Psychological Contract Breach, Organizational Citizenship Behaviour and Work Engagement. Journal of Advanced Nursing, 72, 2806-2817. https://doi.org/10.1111/jan.13043

Hair, J. F., Black, W. C., Babin, B. J., Anderson, R. E., \& Tatham, R. L. (2013). Multivariate Data Analysis (8th ed.). Edinburgh Gate, Harlow: Pearson Education Limited.

Indrawiani, T. O., Anggraeni, A. I., \& Indrayanto, A. (2018). The Influence of Perceived Organizational Support (POS) and Psychological Capital on Organizational Citizenship Behavior (OCB). Jurnal Akuntansi Manajemen dan Ekonomi, 20, 1-4.

Kabasakal, H., Dastmalchian, A., \& Imer, P. (2011). Organizational Citizenship Behavior: A Study of Young Executives in Canada, Iran, and Turkey. International Journal of 
Human Resource Management, 22, 2703-2729. https://doi.org/10.1080/09585192.2011.599943

Katz, D. (1964). Motivational Basis of Organizational Behavior. Behavioral Science, 9, 131-146. https://doi.org/10.1002/bs.3830090206

Katz, D., \& Kahn, R. L. (1966). The Psychology of Organizations. New York: Wiley HR Folks International. http://www.sciepub.com/reference/7502

Kurtessis, J. N., Eisenberger, R., Ford, M. T., Buffardi, L. C., Stewart, K. A., \& Adis, C. S. (2017). Perceived Organizational Support: A Meta-Analytic Evaluation of Organizational Support Theory. Journal of Management, 43, 1854-1884. https://doi.org/10.1177/0149206315575554

Lester, S. W., Meglino, B. M., \& Korsgaard, M. A. (2008). The Role of Other Orientation in Organizational Citizenship Behavior. Journal of Organizational Behavior: The International Journal of Industrial, Occupational and Organizational Psychology and Behavior, 29, 829-841. https://doi.org/10.1002/job.504

Mahembe, B., \& Engelbrecht, A. S. (2014).The Relationship between Servant Leadership, Organisational Citizenship Behaviour and Team Effectiveness. SA Journal of Industrial Psychology, 40, 1-10. https://doi.org/10.4102/sajip.v40i1.1107

Nisar, Q. A., Marwa, A., Ahmad, U., \& Ahmad, S. (2014). Impact of Perceived Organizational Support on Organizational Citizenship Behavior: Empirical Evidence from Pakistan. International Journal of Research, 1, 231-240.

Organ, D. W. (1997). Organizational Citizenship Behavior: It's Construct Clean-Up Time. Human Performance, 10, 85-97. https://doi.org/10.1207/s15327043hup1002 2

Organ, D. W., Podsakoff, P. M., \&MacKenzie, S. B. (2006). Organizational Citizenship Behavior: Its Nature, Antecedents, and Consequences. Beverly Hills, CA: Sage.

Podsakoff, P. M., MacKenzie, S. B., Paine, J. B., \& Bachrach, D. G. (2000). Organizational Citizenship Behaviors: A Critical Review of the Theoretical and Empirical Literature and Suggestions for Future Research. Journal of Management, 26, 513-563. https://doi.org/10.1177/014920630002600307

Pucciarelli, F., \& Kaplan, A. (2016). Competition and Strategy in Higher Education: Managing Complexity and Uncertainty. Business Horizons, 59, 311-320.

https://doi.org/10.1016/j.bushor.2016.01.003

Seligman, M. E., \& Csikszentmihalyi, M. (2000). Positive Psychology. American Psychologist, 55, 5-14. https://doi.org/10.1037/0003-066X.55.1.5

Selvaratnam, V. (2016). Malaysia's Higher Education and Quest for Developed Nation Status by 2020. Southeast Asian Affairs, 124, 199-221.

https://doi.org/10.1355/9789814695671-016

Sunder M, V. (2016). Constructs of Quality in Higher Education Services. International Journal of Productivity and Performance Management, 65, 1091-1111. https://doi.org/10.1108/IJPPM-05-2015-0079

Vivek, S. A. (2016). Impact of Organizational Citizenship Behavior on Managerial Effectiveness. Prabandhan: Indian Journal of Management, 9, 7-18. https://doi.org/10.17010/pijom/2016/v9i2/87228

Zhang, L., Qiu, Y., \& Teng, E. (2017). Cross-Level Relationships between Justice Climate and Organizational Citizenship Behavior: Perceived Organizational Support as Mediator. Social Behavior and Personality, 45, 387-397. https://doi.org/10.2224/sbp.4842 